\title{
A Methodical Approach to Legal Research: The Legal Research Plan, an Essential Tool for Today's Law Student and New Attorney
}

Caroline L. Osborne

Washington and Lee University School of Law, caroline.osborne@mail.wvu.edu

Follow this and additional works at: https://scholarlycommons.law.wlu.edu/wlufac

Part of the Legal Education Commons

\section{Recommended Citation}

Caroline L. Osborne, A Methodical Approach to Legal Research: The Legal Research Plan, an Essential Tool for Today's Law Student and New Attorney, 32 Legal Reference Services Q. 54 (2013).

This Article is brought to you for free and open access by the Faculty Scholarship at Washington and Lee University School of Law Scholarly Commons. It has been accepted for inclusion in Scholarly Articles by an authorized administrator of Washington and Lee University School of Law Scholarly Commons. For more information, please contact christensena@wlu.edu. 
This article was downloaded by: [Washington \& Lee University]

On: 10 October 2013, At: 07:24

Publisher: Routledge

Informa Ltd Registered in England and Wales Registered Number: 1072954 Registered

office: Mortimer House, 37-41 Mortimer Street, London W1T 3J H, UK

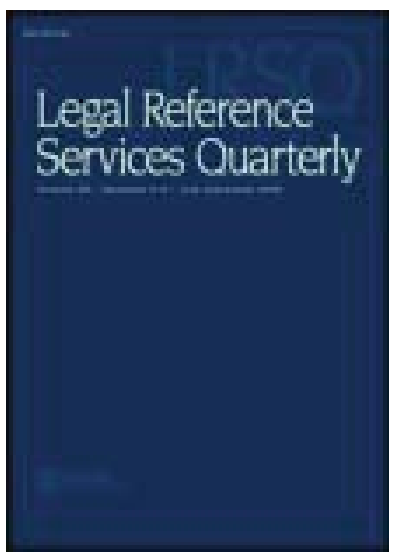

\title{
Legal Reference Services Quarterly
}

Publication details, including instructions for authors and subscription information:

http:// www.tandfonline.com/ loi/ wIrs20

\section{A Methodical Approach to Legal Research: The Legal Research Plan, an Essential Tool for Today's Law Student and New Attorney}

\author{
Caroline L. Osborne ${ }^{\text {a }}$ \\ a Law Library, Washington and Lee University School of Law, \\ Lexington, Virginia, USA \\ Published online: 08 Apr 2013.
}

To cite this article: Caroline L. Osborne (2013) A Methodical Approach to Legal Research: The Legal Research Plan, an Essential Tool for Today's Law Student and New Attorney, Legal Reference Services Quarterly, 32:1-2, 54-77, DOI: 10.1080/0270319X.2013.759041

To link to this article: http:// dx.doi. org/ 10.1080/ 0270319X.2013.759041

\section{PLEASE SCROLL DOWN FOR ARTICLE}

Taylor \& Francis makes every effort to ensure the accuracy of all the information (the "Content") contained in the publications on our platform. However, Taylor \& Francis, our agents, and our licensors make no representations or warranties whatsoever as to the accuracy, completeness, or suitability for any purpose of the Content. Any opinions and views expressed in this publication are the opinions and views of the authors, and are not the views of or endorsed by Taylor \& Francis. The accuracy of the Content should not be relied upon and should be independently verified with primary sources of information. Taylor and Francis shall not be liable for any losses, actions, claims, proceedings, demands, costs, expenses, damages, and other liabilities whatsoever or howsoever caused arising directly or indirectly in connection with, in relation to or arising out of the use of the Content.

This article may be used for research, teaching, and private study purposes. Any substantial or systematic reproduction, redistribution, reselling, loan, sub-licensing, systematic supply, or distribution in any form to anyone is expressly forbidden. Terms \& Conditions of access and use can be found at http://www.tandfonline.com/page/termsand-conditions 
Legal Reference Services Quarterly, 32:54-77, 2013

Published with license by Taylor \& Francis

ISSN: 0270-319X print / 1540-949X online

DOI: $10.1080 / 0270319 X .2013 .759041$

\title{
A Methodical Approach to Legal Research: The Legal Research Plan, an Essential Tool for Today's Law Student and New Attorney
}

\author{
CAROLINE L. OSBORNE \\ Law Library, Washington and Lee University School of Law, Lexington, Virginia, USA
}

\begin{abstract}
This article lays out an approach to teaching legal research through an examination of historical and contemporary approaches to legal research and research instruction. It discusses creating a research plan and reviews the most commonly used legal research texts. It concludes with sample research assignments and assessment tools.
\end{abstract}

KEYWORDS legal research instruction, teaching methodology, legal research texts, legal methods

When asked to quantify their research aptitude, incoming law students frequently answer "adequate or better." Many of those same students would be surprised to learn their teachers and employers consider this assessment of their research skills overrated. ${ }^{2}$ This article argues that one part of the solution to increasing the quality of legal research generally and the research skills of new attorneys and law students specifically is by teaching students a methodical approach to research. The concept of a methodical approach to legal research is not new; it is found in legal research texts in varying forms as far back as the 1940s. The importance of teaching law students and new associates a methodical approach to a research question-one that is strategic and focuses on planning and organization-is an essential skill. This article identifies a method of teaching a deliberative approach to a legal research query that seeks to maximize efficiency and accuracy in the research process. It discusses the use of a legal research plan as the definitive assignment in a legal research class as an assessment tool to evaluate a student's research ability and as a tool for students to internalize a methodical approach to a research problem. The discussion is divided into three parts.

(c) Caroline L. Osborne

Address correspondence to Caroline L. Osborne, Law Library, Washington and Lee University School of Law, East Denny Circle, Lexington VA 24450. E-mail: OsborneCL@wlu.edu 
Part I defines the concept of methodical research and uses real-life examples to illustrate the significance of utilizing such an approach. Part II discusses the history of a methodical approach to research in commonly adopted legal research textbooks. Part III defines the concept of a legal research plan as an assignment and assessment tool.

\section{THE METHODICAL APPROACH TO RESEARCH IN THE WORKING WORLD}

The far too common approach to a research query involves an associate receiving an assignment, sitting down at the keyboard, and randomly typing keywords into Westlaw, Lexis, or Google. "The average attorney will dive into research without thinking. Don't yield to this temptation. Spend the time to just sit and think about your case, to know what questions you should research." "This process generally results in an answer; however, it is usually little more than an answer. This generic example illustrates the accepted research experience of a first-, second-, or even third-year associate. Since the early 1990s, law faculty, attorneys, and law librarians have decried the maturity of summer clerks and entry-level associates to develop, design, and follow efficient research strategies. Real-life examples are telling and underscore the need for a tool that becomes so second nature the attorney fails to realize he or she is utilizing it. In many respects, the art of briefing a case is analogous. For the new law student, case briefing is an unknown tool. Briefing is introduced, customarily, during law school orientation. It has defined steps quickly memorized that, for many, come to be rote by the end of the first semester and certainly by the end of law school. Once ingrained, briefing becomes so much a part of the students' thinking, few even realize they employ it as they read and analyze a case. This is the goal of teaching methodical research-to provide students with a process that is or becomes so internalized they do not even realize they are using it.

Strategy is the planning or conduct of an operation. ${ }^{4}$ In its simplest form, a methodical approach to research is the use of a strategy to locate information on an identified topic. Development of a strategy maximizes efficiency and accuracy through a systematic approach to problem solving rather than focusing on mere serendipity. ${ }^{5}$ There is no single correct form of strategy or plan; however, it is the methodical approach to the query-rather than chance-that elevates the quality of the result. Most often, a researcher may select from a variety of strategies. The knowledge and expertise of the researcher and the nature of the query form the basis for any strategy. Perhaps it is easiest to define what does not qualify as a methodical approach to research. Immediately pulling up your favorite search engine and commencing to type upon receipt of a research project does not qualify as strategic, but rather, it is an example of a shot in the dark. 
Is the preparation of a plan or the creation of a strategy best characterized as a transitional skill for the newly minted associate and law students? Experienced attorneys intimately familiar with an area of the law and the available resources covering such a subject are often able to form a methodical approach to a research problem in their heads. After years of practice honing and developing an area of expertise, they are able to create a strategy for attacking the problem in an organized fashion out of routine and expertise. The experienced attorney has simply internalized the creation of the strategy much like a first-year law student internalizes the ability to brief a case. The skill is not correctly categorized as transitory as the experienced attorney has trained himself or herself to strategize, to think through the elements of a plan, and to methodically employ a plan. It is the process of internalization that is transitory. In place of plotting out a course of action for each and every query, the process has become so ingrained during a period of time that it is rote. This is the ultimate goal.

The following three stories are illustrative. They reinforce the value of thought, structure, and planning prior to action. The names have been changed to protect the innocent.

\section{Carrie}

Chucky was the affectionate nickname assigned by a first-year class to the research hypothetical used for the fall semester research class. Charles Buchanan, also known as "Chucky," was the subject of a rather complicated custody dispute. In one exercise, first-year students were asked to locate the relevant statutory provisions applicable to the elaborate fact pattern provided. Virginia was specified as the jurisdiction of the divorce action and the custody dispute.

"Carrie" knocked on her professor's door one morning close to tears. She was beyond frustrated having spent hours conducting one search after another in the U.S. Code Service (U.S.C.S.) database on Lexis. When the professor asked her to describe her thought process, Carrie responded with a blank stare. When further pressed to describe what she considered prior to typing in a search, she struggled and ultimately responded that she was looking for a relevant statute involving a child and parents who wanted a divorce. She selected U.S.C.S. as they were statutes and ran "child! and divorce." When the professor asked her if jurisdiction was important, Carrie indignantly responded yes. The follow-up question asking why she selected U.S.C.S. as her starting point received the answer of, "It was the statutes database on the classic Lexis home page." A blank stare was the noted response when asked the question of what steps she took to plan her approach to the problem. 
Ben

"Ben," a second-year law student working as a summer associate in a medium-sized law firm, received the project of researching the validity of an assignment of rents in the state of Georgia. He spent hours on Westlaw conducting search after search in the "all state and federal cases" database locating a variety of cases. He proceeded to draft what on its face appeared to be a well-written memo. The first hint of trouble reared its head when the partner noticed the key case cited in the memo was recently overruled. Ben had failed to KeyCite his work. Trouble increased when the partner reviewed the bill for closing, noting, in particular, the excessive Westlaw charges. Ben had spent hours randomly conducting one search after another in an expensive database resulting in excessive and unnecessary search charges. He effectively was throwing things at the wall to see if anything stuck. The ending was not pretty; at the end of the summer, Ben failed to receive an offer.

\section{Andrew}

"Andrew" was a research fellow at a law school. He was engaged by Professor $\mathrm{X}$ to locate materials on an obscure point of law involving property. The request was urgent. Andrew identified the relevant time frame, selected potential treatises most likely to have the information in question, and identified relevant vocabulary associated with the query. Andrew located several relevant passages in the old treatises in a timely manner, making Professor $\mathrm{X}$ happy.

Carrie and Ben both failed to employ any plan prior to conducting their research. Their search strategies were random rather than methodical and were completely lacking in strategy or process. They threw things at the wall to see what stuck only to find frustration and disappointment in the end. Carrie's research question required her to identify the relevant statutory provisions for the Commonwealth of Virginia addressing custody and divorce. A key element to her deliberative process was jurisdiction. This vital element of the search process would have identified the Virginia Code as the choice database or print resource rather than the Federal Code. Use of a methodical process requires Carrie to consider jurisdiction and database selection as elements of a strategy. Her failure to plan or employ some form of strategy to attack the research question resulted in frustration and poor research because she started on an incorrect path with the failure to identify the correct resource required to answer the question.

Ben, like Carrie, failed to engage in any planning process prior to throwing search terms into Westlaw. Planning prior to searching includes consideration of appropriate database selection and the concept of updating research. Had Ben internalized the basic parts of a legal research plan or method, he 
would have considered both the concept of jurisdiction in connection with database selection and the need for KeyCite. In the end, Carrie was frustrated and Ben was unemployed. Andrew had internalized the concept of a methodical approach to his research. He was able to quickly and successfully respond to Professor X's query by quickly considering the appropriate type of sources, relevant vocabulary, and the requisite period of time.

\section{HISTORY OF THE ADOPTION OF THE CONCEPT OF A METHODICAL APPROACH TO RESEARCH}

The names of the commonly adopted legal research texts are familiar: Mersky's Fundamentals of Legal Research, Cohen's How to Find the Law, Sloan's Basic Legal Research, and Kunz's The Process of Legal Research. All are well known and are adopted by professors of legal research. Each of the current editions embodies the concept of a methodical approach to research in varying degrees.

\section{How to Find the Law \\ The earliest conception of an organized approach to a research problem appears in Chapter 11 of the third edition of How to Find the Law published in 1940. ${ }^{6}$ Although far from the developed concept later seen in the Mersky, Cohen, Sloan, and Kunz texts, the notion is there.

\begin{abstract}
To the person who has grasped these fundamentals, an outline synthesizing the methodology in the various publications will be of value as such no doubt will not only aid him in organizing the knowledge in the field of the use of legal materials, but it may also serve as a convenient guide for quick reference in the future. ${ }^{7}$
\end{abstract}

This statement precedes a tool-specific chart and outline detailing where to start and the procedure for updating research based upon type of query and source. The focus is print-driven and centers upon understanding the value of various print resources and strategizing how a particular publication might be used to add value to the research process. The fourth edition elaborates on this theme with an expanded version of the chart of sources suggesting approaches and starting points. ${ }^{8}$ The focus remains on strategizing how to use print sources to their greatest benefit. These early references are the precursors to what ultimately will become a strategic approach. They are important for both the introduction of the planning concept and the era in which the concept of planning and strategy is introduced-the print era. 
Chapter 14 appearing in the fifth edition of How to Find the Law published in 1957 edges closer to the fuller concept of planning found in today's texts. For the first time, factual analysis, issue identification, source identification, updating, and creation of a written record are discussed in detail. The reader also receives a warning.

[F]inding the law involves such a multiplicity of details that the beginner is not only often confused but he is likely to be so impressed with the 'mechanical' features that he overlooks the most fundamental characteristic of legal research. Legal research is essentially an intellectual activity, which simply cannot be carried on, except at the most elementary and routine level, without careful thought. At each step the researcher must make decisions, which either include or exclude information as being relevant to the problem under consideration... There is, however, one constructive factor. The more fully they are understood and mastered, the less attention they require and the more the researcher can concentrate on the substance of the problem.?

In the sixth edition of the text, the information from the fifth edition's Chapter 14 moves to Chapter 1, and the importance of a systematic running record of research is characterized as imperative. ${ }^{10}$ Chapter 2 also contains the threads of the precursor of the methodical approach to research with a discussion on vocabulary focused on development of possible keywords and the importance of synonyms, albeit to be used with an index or a table of contents. ${ }^{11}$ In 1976, the first directive to plan research appears. "Plan your research; ... [Y] ou can plan your research so that you utilize your time, your library's resources, and the resources of other libraries-all in a coordinated and effective manner."12 It is in the eighth edition of the text, however, that the concept of a research plan first appears.

With such a research plan, including lists of sources to be consulted, finding tools to be used and search words and phrases to be employed, one can then begin the actual research. As each source and research tool is examined, it is checked off the list and the results noted. Thus, crucial omissions can be prevented and the retracing of steps avoided.... As the results of these steps become apparent, the plan can be modified or redirected. One need not be bound by the initial strategy, or locked into an unproductive approach.... Legal research can be both organized and creative. Imagination, serendipity and the flash of seemingly spontaneous insight are more likely to occur in the course of systematic research than in the random consultation of unrelated sources. ${ }^{13}$

By the most recent edition of How to Find the Law, the concept of the research plan or a methodical approach to research is complete. Cohen calls for a flexible but formulaic approach specifying five steps: 1) analysis of 
the facts and framing of the legal question, 2) obtaining an overview of the subject area, 3) searching legal authority, 4) reading and evaluating primary authority, and 5) updating the research. ${ }^{14}$

\section{Fundamentals of Legal Research}

The concept of a planned search appears as early as 1956 in the Fundamentals of Legal Research. ${ }^{15}$ Chapter 2 delineates three discrete steps in the research process: 1) factual analysis, 2) issue identification, and 3) location of legal authority. ${ }^{16}$ Chapter 20, "A General Summary of Research Procedure," of the same edition outlines research based upon the nature of the issue-statutory, case, or administrative query. A chart, based upon the type of research query, directs the researcher to the appropriate source. ${ }^{17}$ This same approach continues until 1977 when Chapter 20 (now Chapter 24) appears extensively revised. The new Chapter 24 begins to suggest the concept of methodical research as we think of it today. "The final step in our study is to develop a systematic approach to problem solving using these research tools." ${ }^{18}$ The recommended strategy includes identification of operative facts, determination of legal issues, identification of relevant sources, and communication of the results. ${ }^{19}$ Pollack's chart of sources from the 1956 edition is included within the discussion of identification of relevant sources of law. ${ }^{20}$ The fifth edition published in 1990 deletes the chapter titled "A General Summary of Research Procedure," which appeared as Chapter 20, 24, or 25 in the prior editions of the work, and replaces it with a revised Chapter 2 . The revised Chapter 2 begins by acknowledging that there are varying methods of research depending upon the nature of the problem and the researcher's expertise in the subject. ${ }^{21}$ Four elemental steps of a strategic approach to research are outlined: factual analysis, issue identification, researching relevant issues, and updating research. ${ }^{22}$ This approach is retained in the subsequent editions up to and including the current edition, the eighth edition, with one addition. Pollack's chart of sources is added back as an appendix beginning with the sixth edition.

\section{Kunz's The Process of Legal Research}

The Process of Legal Research was first published in 1986. It contains one of the most complete conceptualizations of a methodical approach to research available in a legal research text.

Legal research requires more than a familiarity with the major research sources and a map of the library. Legal research is really legal problem solving. Successful legal research largely depends upon developing a research approach that combines (1) factual analysis based on legal 
categories with (2) deductive and inductive reasoning in the use of primary and secondary authority and finding tools. Successful researchers continually reevaluate their research methodology and consider alternative research approaches as they find that various sources or research approaches are helpful or fruitless. Even the most diligent researcher, armed with the latest technology, will not arrive at a successful result if he or she approaches legal research as a mechanical process devoid of analysis. ${ }^{23}$

The third edition of the text builds upon the theme of deliberative analysis. Indeed, Chapter 1 begins with a flow chart of an analytical approach capturing the steps of identifying search terms, obtaining background information, formulating issues, and reading and analyzing primary authority. Chapter 2 extensively builds upon the concept of research as a strategy.

Legal research is a skill you are learning in order to enhance your ability to solve legal problems.... To become proficient at choosing and gaining access to legal research materials you must analyze the legal problem being worked on, the strengths and weaknesses of the available sources, and your own areas of knowledge and ignorance. This analysis must continue all the way through the research process.

A good researcher envisions legal research as a set of research 'game plans' (or strategies) and knows when to select which strategy... Your research strategies should be flexible....[E]ven the most diligent researcher, armed with the latest technology, will not be successful if he or she approaches legal research with a mechanical checklist devoid of flexibility and analysis. ${ }^{24}$

The authors outline ten basic steps of a strategy. The steps include factual analysis, generation of relevant vocabulary, obtaining an overview of the topic, issue identification, and location of primary authorities. ${ }^{25}$ Perhaps most interesting in comparing editions of the Kunz text is that the third edition contains the most extensive discussion of a strategic approach to research. The subsequent fourth, fifth, and sixth editions published in 1996, 2000, and 2004, respectively, although still strongly advocating a deliberative approach, lack the comprehensive discussion of the third edition's Chapter 2. In the subsequent editions, the detailed analysis is replaced with a more succinct examination of the process and an elaborate dialogue on generation of research terms. ${ }^{26}$

\section{Sloan's Basic Legal Research}

Currently in the fourth edition, Sloan's Basic Legal Research text includes one of the most recognizable discourses on the legal research plan. Sloan 
recognizes the fluidity of the research process yet suggests an approach with general steps adaptable to any query. She directs the researcher to: consider the scope of the project including any time limits; generate search terms; recognize the end product to be generated; identify potentially useful sources, the intended sequence of use, and any restrictions on use; and specify the jurisdiction. ${ }^{27}$ Her recommended approach remains relatively unchanged from that appearing in her first edition in $2000 .{ }^{28}$

Examination of How to Find the Law, Fundamentals of Legal Research, The Process of Research, and Basic Legal Research confirms that the concept of utilization of a plan or a strategy is nothing new. Indeed, the fact that the seminal texts advocate such an approach at the height of the print research era is, perhaps, the most illuminating fact. Given the generally accepted explosion of available information in today's world, it highlights the concern articulated in the Chicago Area 2007 Attorney Survey: "there will be even more information available online than there already is, and it may become difficult to sift through it all to get at what is important." ${ }^{29}$ If a planned approach to a query is imperative in a largely print-based era, as suggested in Cohen's sixth edition, with the explosion of access to information due to advances in technology in today's Google-driven world, is a methodical approach to research not even more critical now than then? This is even before we factor in the question of information literacy and the quality of basic research skills possessed by incoming law students. Research is more than words on a screen. The ability to compose a search in Westlaw, Lexis, or Google does not translate into being a good, or even competent, researcher. Research is a complex, intellectual activity that requires students to exercise their minds, hone their analytical skills, and make valid and accurate distinctions. Good research builds confidence.

Acknowledging the need to create and use a strategy before attacking a research query is the easy step. Getting students to adopt the technique is the more difficult challenge. Today's student is indoctrinated by Google to simply bring up the page and start typing. Consider these comments from respondents from a 2007 survey of attorneys on new associate research skills.

$[\mathrm{M}]$ ore and more reliance on keyword database searching, and less resort to books-not necessarily a good thing because young associates often fail to develop concepts as a result of the myopic use of keywords.

Google is, of course, a technical triumph and a useful tool for finding some types of information. The problem with the Google approach for nascent legal researchers is in its oversimplification of the research process. Google [teaches] us that it is no longer necessary to go through the effort of defining our information need. We just put a word or two into the search box and let a search engine disambiguate the query and provide an answer. ${ }^{30}$ 
People trust online resources more and use Google-type searches on a daily basis.

[S]tress the fact that the best research works with a refined search strategy as opposed to a 'shotgun' approach which will yield multiple hits. It is a good idea to sit down and think about what you want and sometimes more importantly, what you don't want. ${ }^{31}$

The Google habit is not easily broken. WestlawNext and Lexis Advanced do little to assist legal research professors in curbing bad habits.

It is Google's ability to take thought out of the research process that might cause law students to fail as legal researchers: they might be able to find information, but they might not understand what they have found. As Professor Molly Lien has noted, 'students appear to equate the ability to access the material with mastery of the material. They view downloaded information as learned information. ${ }^{32}$

Inclusion of the methodical approach to research in the framework of the first-year research class is essential. The classroom and imprimatur of the instructor provide needed credibility for the structure as well as an opportunity for the student to use the approach, to see the resulting benefits, and to internalize the approach for future use. The legal research plan is used as the instrument to teach the approach and illustrate the associated benefits, and it provides the method to be internalized.

Efficiency and accuracy are the identifiable benefits to creating and following a strategy, methodology, or plan. The mere act of taking the time to create a plan and organize your thoughts increases both the efficiency of the search and the accuracy. Planning minimizes the risk that important authorities or resources are missed or overlooked. The old adage "time is money" is especially true for lawyers. Research is expensive. It takes time to do quality analysis and research, and the rate for a billable hour is not cheap. Resources also have associated costs. This requires attorneys to be efficient and accurate. Using an example such as Ben's story drives home the importance of not only research generally, but the need for quality research in particular. The fact that Ben's failure to receive an offer of employment directly due to his shoddy research is a fact students grasp. Many first-year law students seek the comfort of structure; thus, emphasizing the concept that planning or strategy can provide a structure that promotes "confidence that your research is correct and complete" is a lifeline many will grab. ${ }^{33}$ Emphasizing the resulting inefficiency when a "clear understanding of the specific steps you should take to solve the problem" is lacking ${ }^{34}$ also assists in the promotion of acceptance. Providing examples from those working in the profession will also provoke acceptance. Mark Herrmann notes in This 
is What I'm Thinking: A Dialogue Between Partner and Associate that "most new lawyers begin their legal research by turning on a computer; [t]his is almost invariably wrong. When you work for me, do not begin your research with a computerized database unless I expressly tell you to do so."35

Buy-in from writing faculty is additional reinforcement of the case for use of a deliberative approach to research.

Good researchers have to be good writers to present the fruits of their investigation to the scholarly community effectively. Therefore, the help we can offer students has to take into consideration all the elements of success: finding information, understanding and analyzing it, and presenting it in writing. 36

The writing process is the largest beneficiary of using a systematic approach to research. First-year students often fail to grasp the symbiotic nature of writing and research. "Legal research informs legal writing and legal writing is meaningless without accurate content." ${ }^{37}$ This quote best summarizes the interconnection between research and writing. You research to know the law and to develop a position or argument, and to provide advice. You write to convey the law to another. Too often these are viewed as separate processes that fail to connect. This is a mistake. The processes are intertwined in the most basic sense. The attorney conceives the initial argument and then must locate the authorities to support that position. As he or she researches, he or she refines the argument based on the actual law. The process is symbiotic - researching, writing, refining, writing, and research until the final product is completed.

\section{METHODOLOGY OF ADOPTION-THE LEGAL RESEARCH PLAN AS AN ASSIGNMENT AND ASSESSMENT TOOL}

Incorporation of the Legal Research Plan into the First-Year Legal Research Curriculum

The legal research plan is the definitive assignment in the first-year legal research program at Washington and Lee University School of Law. The firstyear research program is two semesters. The fall semester focuses on case law, statutory research, and secondary resources. The spring semester builds on the fall semester and introduces administrative resources, legislative history, and practice materials. The legal research plan is the final assignment of the spring term. As a tool, it has the ability to tie the two semesters together and simulate a real-life example of a complex research project. It also supports the goal of training a law student or new attorney to think about the process of research furthering the internalization of the method by the student. The assignment emphasizes the material from the spring semester while 
reinforcing basics of statutory materials, case law, and secondary resources. The assignment uses research questions with a focus on either legislative history or administrative law. It is designed to be comprehensive. Students may use any available resource.

Developing the assignment requires clear and concise instructions including finite time for completion of the project. Seventy-two hours to complete the project and produce a written memorial of the plan is the recommended time frame. This attempts to balance competing demands of a first-year student's schedule and provide a realistic period to complete the preliminary research and compose the written plan. Rarely do practicing attorneys have unlimited amounts of time to research a question. Failure to provide a finite time limit undercuts the simulation aspect of the assignment and promotes endless wandering. The questions are designed to permit development of a comprehensive research strategy and preliminary research of the issue or issues by a first-year student in approximately twelve hours.

During the final class period of the spring semester, first-year students receive the problem and instruction memorandum with detailed guidelines for the project. A sample of the memo is reproduced in Appendix A of this article.

A sample problem prompt from prior exercises is reproduced here. The problem involves a federal regulatory issue due to the focus of the spring semester. Care is also given to create a problem that is timely. The grading rubric for the problem is included in Appendix B.

Dear Associate,

Below is some background information on the legal situation faced by one of our biggest clients. I will be traveling extensively over the next few weeks and I am relying on you to develop a research plan for me. Upon my return, I will conduct the research using your plan and then draft the necessary memoranda for both the firm and client. I need you to 'grab the bull' on this one and work independently. I will be available on a very limited basis for procedural questions, but I don't know anything about this topic so I cannot be of any assistance with regard to substantive legal issues-this is why I need your research plan!

Here is what we know about our client's situation. In the fall of 2008, EIG, Inc. received a massive bailout from the federal government through the Troubled Asset Relief Program (TARP). You represent EIG's board of directors (the "Board"). EIG's CEO's contract is up for renewal in May of 2011. The Board's compensation committee is scheduled to meet on April 1, 2011 to consider the existing CEO's compensation package. The Board is generally aware, from stories in the news, of restrictions on executive compensation. The Board's intent is to comply with all 
applicable laws. The company, Board, and CEO desire to treat compensation matters as private, if possible. Your assignment is to create a comprehensive research plan that will allow a senior partner to advise the Board of what, if any, information regarding an executive compensation package must be disclosed as a result of any federal law passed since EIG accepted the TARP funds in 2008. Please note your assignment addresses the disclosure of information regarding executive compensation by TARP recipients. Another associate is addressing the issue on actual restrictions on executive compensation by TARP recipients.

The firm is counting on you to impress our client and get this resolved efficiently. Do not forget, we only have seventy-two (72) hours available for you to bill. You will need to track your time and bring this product in within budget.

The two most challenging aspects of creating this assignment are problem development and grading. Finding an interesting and current topic and transforming it into a problem a student can successfully research in twentyfour hours is often daunting. It is preferable to select a topic that has developed a certain maturity. A mature topic is one that has, at a minimum, a case, a statute, or a final regulation and a variety of secondary resources on point. Legal blogs and newspapers are excellent resources for suggestions. Immature topics are those that lack information. Cases may not have percolated to the point of an opinion, and regulations may still be on the drawing board and not introduced for notice and comment, much less moved to the final stage. It is preferable to select a topic that assesses a student's ability to research any issue. It is also advisable to avoid topics of immense political debate. Such topics lend themselves to advocacy memos rather than research memos.

Consistently grading in excess of 100 plans is also a challenge. To promote consistency, a model grade sheet is developed for each plan. The model identifies the seminal authorities to be located and allocates the maximum point value for that part of the plan. The grade sheet used for the EIG problem is reproduced in Appendix B. Use of a grade sheet assists to keep the grader honest. Due to the size of the first-year class at Washington and Lee, three separate prompts are used. This inserts a variance into the mix. Using a standard rubric for grading minimizes the impact of three different topics.

\section{The Legal Research Plan as an Assessment Tool}

In the context of education, the Oxford English Dictionary defines assessment as "the process or means of evaluating academic work; an examination or test." ${ }^{38}$ Assessment, as used in this discussion, is a tool to provide information to both the student and the professor and to identify areas 
for improvement. This is not a unique concept; teachers regularly collect information on students' successes and failures. ${ }^{39}$ Schwartz's suggestion that "assessment and learning are intricately connected" is correct. ${ }^{40}$ "Students learn when they have a sense of that they are setting out to learn." ${ }^{41}$ Building upon Schwartz's and Munro's suggestions, learning is increased when identified standards for good research are provided in advance and students are evaluated on the basis of such standards. ${ }^{42}$ Consistent with this suggestion, the Washington and Lee first-year research program provides each student a list of learning objectives for each discrete component of the program. Likewise, accompanying the legal research plan assignment are detailed guidelines and a generic grading rubric identifying key parts of the research plan assignment with associated point values. A copy of the generic plan is reproduced in Appendix C. The guidelines and the generic rubric serve the dual purposes of providing students a clear statement of what they are expected to take away from the assignment and providing the basis of the evaluation.

Adapting Munro's suggestion of a successful law school three-part assessment program, a successful assessment tool for a legal research program will meet two goals:

1. Assessment is viewed as a tool to enhance student learning;

2. Assessment will determine the program's success or deficiencies and serve as a measure of the program's effectiveness. ${ }^{43}$

The legal research plan assignment is designed to meet each stated goal. The plan is a tool designed to enhance student learning by obligating students to put it all together within the context of a simulated research assignment. It requires students to demonstrate their ability to engage in legal analysis, issue spot, and identify and use basic library resources to problem solve. The assignment is 1) comprehensive, requiring students to draw on all the research skills taught during the first year; 2) simulated, requiring students to demonstrate the ability to research a complex legal problem in the manner of a summer associate in a law firm or a first-year associate; and 3) evaluative, as it provides students with significant feedback on the project in a timely manner prior to the end of the semester. The feedback provides a meaningful opportunity for the student to learn from his or her mistakes in a nonthreatening environment and is designed to improve and further the learning process.

The second goal is directed at an evaluation of the program as a whole and provides meaningful information to correct deficiencies within the program as well as an assessment of the effectiveness of the problem. Reviewing in excess of 100 plans provides an opportunity to identify trends, holes, and general missteps in the overall legal research program. Examples of gaps from prior years have found deficiencies with the ability to correctly identify materials as either mandatory or persuasive and their properly associated 
uses and the ability to use an index. This information was subsequently used to enhance instruction on these topics.

Michael Schwartz suggests eight factors to consider when preparing an assessment tool:

1. What is the rationale for the assessment?

2. What do you want students to do?

3. How much time will it take for students to complete?

4. Will the assessment be completed in or outside of class?

5. What is the assessment's content?

6. Is there a particular form students should use?

7. How much can students collaborate on the assessment?

8. How will you provide feedback? ${ }^{44}$

The plan as an assignment and as an assessment tool addresses each of the eight factors. The rationale for the assessment is to evaluate the overall success of the research program in meeting the identified course goals and the ability of the student to successfully apply the research skills taught during the first year. The desire is for students to take a complex, simulated research problem, analyze the facts, issue spot, identify useful sources, and reach a preliminary conclusion. Students are given a finite amount of time to complete the project much like they might face within the actual practice of law. The assignment is completed outside of class. Content of the assignment focuses on an issue of administrative law or legislative history with a secondary and broader focus on case law, statutory materials, and secondary resources. Students are provided a suggested generic form of research plan, related reading discussing the elements of a research plan, and a questionand-answer period regarding the structure of the assignment. Collaboration is prohibited, which is a departure from the real-world aspect of the assignment because in reality, many research projects are collaborative and involve multiple associates working on discrete aspects of a client's matter. These parameters of the assignment are specified in a detailed memorandum of instruction; see Appendix B for an example.

Feedback is provided in two primary approaches. The first method is through use of a standardized evaluation rubric for each problem. The second is by use of marginal comments. Students are also provided the opportunity to meet with the professor to discuss their work.

The generic plan and the related course goals recognize the following assumptions:

1. Law students should be able to conduct competent research at the conclusion of the first year of law school. 
2. The program has successfully articulated goals making known the requirements for excellence in legal research.

3. The ability to conduct legal research is a core requirement to the successful practice of law and success in the chosen profession of a law student.

4. Assessment of a student's ability to engage in competent research and assessment of the program as a whole are integral to the success of the student and the program. ${ }^{45}$

These assumptions build upon the MacCrate Report's suggestion that problem solving, legal analysis and reasoning, and legal research are "outputs of legal education." ${ }^{46}$ Similarly, they track Judith Younger's suggestion that successfully trained lawyers possess the ability to:

1. issue spot;

2. apply correct legal labels to and characterize the facts of a case;

3. use the law library and all sources provided to their greatest advantage; and

4. write using correct grammar. ${ }^{47}$

The goal of any successful assessment is to improve learning be it from the student's or professor's perspective. The plan is intended to be a tool to further the student's learning experience, provide an evaluation of the student's ability to engage in research, and evaluate the research program as a whole in its effectiveness in teaching students legal research skills. As such, the plan provides coherence to a two-semester program and provides a meaningful measure of the pedagogy utilized within the structure of the program. It is used as a measure and is actual evidence of achievement or lack of achievement of the stated goals of the first-year program. ${ }^{48}$

Assessment tools are usually characterized as either formative or summative. The end purpose is to improve learning by identification of trends for competence and deficiencies. "A formative tool is designed to facilitate the student's learning and provide extensive feedback." 49 The purpose of the formative assessment tool is to assist the student in learning rather than to assign a grade. The defining characteristic of a formative assessment tool is repetition. A formative tool provides frequent opportunities to permit students to illustrate what they are learning, or not, and to improve. Examples of formative assessment tools include the minute paper and the pop quiz. A summative tool assesses knowledge at the end of a course and provides information on how well the student met the identified course objectives. ${ }^{50}$

In contrast to a formative tool, the summative tool is a mechanism for feedback and is not a learning tool for the student, although it can be for the teacher. ${ }^{51}$ The final essay exam is the traditional assessment tool for most doctrinal courses in law school and is an example of a summative form of assessment tool. It measures the degree of success to which students achieved 
the stated course goals and often is the sole basis of the semester grade. The essay exam is not used as a diagnostic tool or device to improve student learning during the course. ${ }^{52}$ Formative assessment tools are preferable to summative tools for the learning experience due to their ability to provide immediate feedback and opportunity for course correction. ${ }^{53}$

Effective assessment tools should: 1) correspond with the subject of the assessment, and 2) provide feedback to students to further learning. Also, they should be evaluated based upon concepts of validity and reliability. Validity means the tool must "effect or accomplish what is designed or intended." ${ }^{54}$ In the context of a law school summative tool, this means, does the tool measure whether the course goals and objectives were met? ${ }^{55}$ Reliability asks if the tool, upon repetition, provides consistent results. ${ }^{56}$ Reliability also requires consistency in scoring. ${ }^{57}$ The legal research plan as an assessment tool embodies the constructs of both validity and reliability. The properly drafted assignment tracks to identify course and assignment goals and measures the ability of the student to demonstrate knowledge of research goals within the context of a complex research problem. The overarching stated goal of the research program is the ability of a student to demonstrate mastery of basic research in the areas of case law, legislation, and administrative law including the ability to identify appropriate primary and secondary resources, analyze the problem, and identify relevant sources of information. Thus, a valid assessment tool requires demonstration of analysis, knowledge of basic sources of law and information, and the ability to apply the techniques of analysis and the knowledge of sources in a simulated context. The plan demonstrates the characteristic of reliability as it produces consistency of results when measured against a consistent rubric.

The legal research plan is a hybrid tool because it combines features of both formative and summative assessment tools. It is formative in structure because it is the last in a series of assignments administered throughout the year that build to the final assignment. It builds upon each of the smaller prior assignments. This meets the repetitive characteristic of a formative assessment. Throughout the two semesters, students are provided mini research problems that reinforce the various tools and skills of legal research and are consistent with the stated objectives. The plan is the final assignment and requires students to demonstrate mastery of the skills learned during the entire year. It also demands students demonstrate use of those skills in a simulated context and provides students the opportunity to receive feedback on a comprehensive research project with a unique focus on the research. In this manner, the tool also retains formative assessment characteristics.

The plan also possesses summative characteristics. It is intended to be summative in nature and to provide a comprehensive measure of the success of the entire first-year class in meeting the stated learning objectives. As such, it is a meaningful tool for the professor to identify deficiencies and successes. The assignment measures the student's ability to research a complex problem 
in a simulated situation. It is too simplistic to suggest the research plan is a traditional essay exam. Essay exams generally require a student to recall material and generate an answer in a brief time period. The plan is more akin to a performance examination than a traditional essay exam. Performance exams test a range of skills including analysis and application as does the legal research plan assignment.

\section{CONCLUSION}

In today's world, with information literally at one's fingertips and an environment of information overload, a methodical approach to a research problem is essential to a quality research experience. The digital natives of today and tomorrow excel at Googling anything and everything. Educating the current generation of students in a more refined approach to research requires breaking exiting habits. This article suggests the need for students to internalize a methodical approach to any research query. Instilling in students the need to think before they search, create a strategy, and plan an approach to the problem is the initial step in breaking poor, and often existing, research habits. Teaching students to adopt and internalize the concept of a methodical approach to research within the first-year legal research program is essential for the development of quality research skills by today's law student. Use of the legal research plan as an assignment is the recommended tool for introduction of the methodical approach. Incorporating and repeating the concept that some form of examination of the elements of a basic research plan is the first step in the research process to the point of internalization is the ultimate goal.

The research plan as an assignment is a successful assessment tool combining elements of both formative and summative tools. In this manner, it is an instrument to provide instructors and students with information needed to improve the research experience for the individual student and the program as a whole. Effectively used, it can serve to further student learning through critique of a simulated complex problem. Simulation of a real-life research problem requires the student to demonstrate his or her skills and provides an opportunity to identify and correct weaknesses. The tool is also valuable to the professor as it provides an opportunity to detect strengths and deficiencies within the program and to adjust.

\section{NOTES}

1. Ian Gallacher, 'Who are Those Guys?': The Results of A Survey Studying the Information Literacy of Incoming Law Students, 44 Cal. W. L. Rev. 151, 154 (2007). See also Kathryn Hensiak et al., Assessing Information Literacy Among First-Year Law Students: Final Technical Report 2 (2004) (copy on file with author). Seventy-one percent of incoming first-year law students surveyed rate their library research skills as excellent, very good, or good. $I d$. 
2. Id.

3. Duane Ostler, The Strength Is in the Research, 20 Utah B. J. 42, 43 (2007).

4. The American Heritage Dictionary of the English Language 1273 (William Morris ed., New College ed., Houghton Mifflin 1978).

5. Steven M. Barkan et al., Fundamentals of Legal Research 14 (9th ed., Foundation Press 2009).

6. Henry J. Brandt, How to Find the Law: A Comprehensive Treatment of the Problems of Legal Research with Illustrative Pages from Numerous Publications Together with a Legal Bibliography for each State and the Federal Government 179 (3d ed., West Publishing Co. 1940).

7. Id. at 180 .

8. Carlton B. Putnam, How to Find the Law, A Comprehensive Treatment of the Problems of Legal Research with Illustrations from Various Publications, Together with a Legal Bibliography for each State and the Federal Government: A Legal Reference Handbook 312 (William R. Rolafe ed., 4th ed., 1949).

9. How to Find the Law 195 (William R. Roalfe ed., 5th ed., 1957).

10. How to Find the Law: With Special Chapters on Legal Writing 6 (William R. Roalfe ed., 6th ed., West Publishing Co. 1965).

11. Id. at 17,21 .

12. How to Find the Law 352 (Morris L. Cohen ed., 7th ed., West Publishing Co. 1976).

13. Id. at 385-386.

14. How to Find the Law 591 (Morris L. Cohen ed., 9th ed., West Publishing Co. 1989). The Principles of Legal Research (successor to How to Find the Law, 9th ed.) addresses the concept of the research process in $\$ 1.4$ Handling a Research Project. The approach discussed is general rather than methodical and lacks the formulaic approach advocated by Cohen. Kent C. Olson, Principles of Legal Research 24 (successor to How to Find the Law, 9th ed., West Publishing Co. 2009).

15. Erwin H. Pollack, Fundamentals of Legal Research (2nd ed., Foundation Press 1956).

16. Id. at 14

17. Id. at $467-476$.

18. J. Myron Jacobstein \& Roy M. Mersky, Fundamentals of Legal Research 488 (successor volume to Pollack's Fundamentals of Legal Research, 4th ed., Jacobstein \& Mersky eds., Foundation Press 1977).

19. Id. at $488-502$.

20. Id. at $491-500$

21. J. Myron Jacobstein \& Roy M. Mersky, Fundamentals of Legal Research 15 (5th ed., Foundation Press 1990)

22. Id. at 15 .

23. Christina L. Kunz et al., The Process of Legal Research 4 (Little, Brown and Company 1986)

24. Christina L. Kunz et al., The process of Legal Research: Successful Strategies 14 (3d ed., Little, Brown and Company 1992).

25. Id. at $14-15$.

26. See generally Christina L. Kunz et al., The Process of Legal Research (4th, 5th, and 6th eds., Little, Brown and Company/Aspen 1996-2004).

27. See generally Amy E. Sloan, Basic Legal Research Tools and Strategies 9-12, 305-306 (4th ed., Wolters Kluwer 2009).

28. Amy E. Sloan, Basic Legal Research Tools and Strategies (Aspen Law and Business 2000).

29. Sanford N. Greenburg, Chicago-Area Attorney Survey (2007).

30. Gallacher, supra n. 1, at 191.

31. Id.

32. Id.

33. Sloan, supra n. 27 , at 305.

34. Mark K. Osbeck, Impeccable Research: A Concise Guide to Mastering Legal Research Skills 7 (West Publishing Co. 2010).

35. Mark Herrmann, This is What I'm Thinking: A Dialogue Between Partner and Associate, 25 Litig. 8 (1998)

36. Michael Hunter Schwartz et al., Teaching Law by Design, Engaging Students from the Syllabus to the Final Exam 6 (Carolina Academic Press 2009).

37. Barkan et al., supra n. 5.

38. Oxford English Dictionary 710 (R. W. Burchfield ed., 2nd ed., Clarendon Press 1989).

39. Schwartz et al., supra n. 36, at 135 . "The truth is, as teachers, we already conduct ongoing assessment: collecting information about student learning." Id.

40. Id. at 135 . 
41. Greg Munro, Outcomes Assessment for Law Schools 15, available at http://lawteaching.org/ publications / books / outcomesassessment / munro-gregory-outcomesassessment2000.pdf (last accessed Feb. 8, 2012).

42. Id. at 15 .

43. Id . at 100. "[A] law school assessment program will have three major aspects: (1) assessment as a tool to measure student learning, (2) assessment to determine program success, and (3) assessment to measure the institutional effectiveness." Id.

44. Schwartz et al., supra n. 36, at 129 .

45. See generally Munro, supra n. 41, at 12-14 (for the underlying assumptions of the assessment of legal education).

46. American Bar Association, Legal Education and Professional Development - An Educational Continuum, Report of the Task Force on Law Schools and the Profession: Narrowing the Gap (American Bar Association 1992).

47. Judith T. Younger, Legal Education: An Illusion, 75 Minn. L. Rev. 1037, 1039 (1990).

48. See generally Munro, supra n. 41, at 4 (discussion of need for outcomes and assessment in law schools).

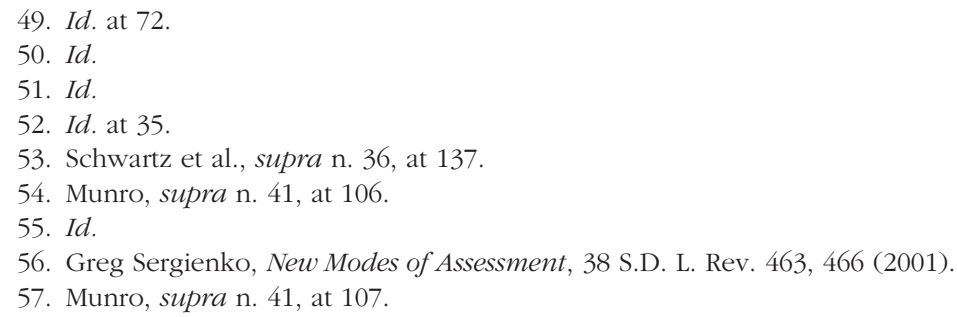

\section{APPENDIX A}

This memorandum provides the guidelines and instructions for the Legal Research Plan (herein, the "Plan"). The Plan is the final assignment for the Spring Semester Burks Scholar Legal Research course. The Plan is due to Ruby Bright by 4 p.m. on March 23, 2012. It is worth 100 of a possible 200 points for the semester. The instructions in this memorandum cover the format and requirements for the Plan. For additional details, please contact your Burks Scholar.

Assignment: You are to create a written legal research plan for the hypothetical situation provided by your Burks Scholar and attach it as Addendum A to this memorandum. The Plan should:

1. clearly identify the relevant issues presented by the hypothetical;

2. set out a methodology for researching those issues; and

3. provide basic or preliminary answer(s) to the question(s) presented.

In addition, the Plan should detail each step in the research process and contain citations to all sources included in the Plan. You are not expected to include final conclusions; however, you are expected to provide sufficient information to adequately address all of the issues presented by the hypothetical and a preliminary conclusion. To the extent required to support the logical progression of the research process, you should include analysis 
sufficient to provide a basis for the Plan. In essence, another person should be able to look at your Plan, perform each step of the Plan, and write a complete legal memorandum about the issue.

Please note the focus of the Plan is the research process together with the underlying sources. You are writing a plan detailing a strategy for researching a legal question, not a memorandum of law.

Format: The Plan should be presented in either memorandum format, similar to this memorandum, or in outline form with appropriate headings. It should be single-spaced in Times New Roman twelve-point font with one-inch margins. Your plan should be a minimum of three pages and a maximum of five pages in length. If you elect to use "outline style," you must use complete (and grammatically correct) sentences, and the end result must be a "professional" product. The Plan should be adequately cited using the proper Bluebook memorandum form. Any citation included should be in Bluebook format. You should include a concise statement of facts and relevant issues, and a preliminary conclusion.

Time: You are limited to seventy-two hours to research the issues and compose the Plan. Time begins at the point you open the assignment envelope. You are responsible for maintaining a record of your time. Submission of the assignment constitutes a pledge that you have not exceeded the seventytwo-hour time limit. The time limit applies to both the research and writing components of this exercise. It is anticipated that you can adequately research the problem in twelve hours. You may not work with a partner on this assignment. Submission of your Plan is a pledge that the work is your sole product. Librarians and Burks Scholars may provide limited assistance.

Resources: You may use print and online resources to complete the Plan. Please use print resources with the knowledge that other members of the first-year class have similar needs.

Westlaw, Lexis, WestlawNext, and Lexis Advance: If you elect to use one or more of these services, you are required to attach to your Plan complete copies of all related research/history trails.

\section{APPENDIX B}

Student:

Total Points $/ 100$

I. Preliminary Methodology (20 points)

a. Issue(s) correctly identified and concisely stated (What information must EIG make public or what information may EIG refuse to disclose?). (4) 
b. Client and objective identified (i.e., what does the client want the lawyer to do for them? Client is EIG's Board of Directors. Objective is to provide senior partner with information to permit him or her to advise the board. Senior partner's advice is most likely oral; however, senior partner requires a written comprehensive research plan from you. The answer may include a memo or an advisory letter to the client). (4)

c. Clear statement of facts (EIG is recipient of Troubled Asset Relief Program bailout funds. EIG is negotiating new compensation package for existing CEO; concise, objective, accurate). (4)

d. Identification of need for additional facts (some of the implementing regulations may require a few additional facts, especially about shareholders, and missing facts should be noted). (4)

e. Jurisdiction identified (show the scope of your research, show where and to whom your results will apply-jurisdiction is federal). (4)

Subtotal I

II. Methodology and Authority (50 points)

a. Statement of strategy (how will you best spend your time to benefit your client; how will you approach the problem?) (20)

1) Search terms (rich, thoughtful, useful). (5)

2) Potential sources (list the potential sources and why they would be relevant to the research question, as well as their level of authority-Federal Statutes-U.S.C., U.S.C.A., U.S.C.S., C.F.R., F.R. for corresponding regulations). (5)

3) Discussion of use of source and why within context of strategy (why does this potential source's relevance, authority, etc. make it a good source for this assignment?) Problem is based on a Federal statute and corresponding regulations. Locate the primary authority and use it as basis to answer question. Secondary sources useful to interpret primary authorities. (10)

b. Identification of primary authority (list mandatory sources identified as actually useful or sources you must address and why). (30)

1) Dodd-Frank Wall Street Reform and Consumer Protection Act, Pub: L. No. 111-203. The act amended the Securities Exchange Act of 1934 by inserting section 14 A after 15 U.S.C. $\S 78$ n, as 15 U.S.C. $\S$ 78n-1. (8.5)

2) Agency implementation: S.E.C. Release No. 9178; S.E.C. Release No. 9153; S.E.C. Release No. 29463; S.E.C. No-Action Letter to Altera Corporation, 2011 WL 190597; 17 C.F.R. $\S \S 229$ (especially $\S$ 229.402), 240, 249. (6.5)

3) Identification of secondary authority (list sources identified as actually useful and why useful [i.e., points to primary authority, explanatory]). (15) 
a) Legislative history: Conference Report: June 29, 2010, Dodd-Frank Wall Street Reform and Consumer Protection Act, H.R. Conf. Rep. 111517. Presidential statement: July 21, 2010, P.L. 111-203, Dodd-Frank Wall Street Reform and Consumer Protection Act, 2010 U.S.C.C.A.N. S26. Other legislative history is listed in the topic proposal. (8.5)

b) Secondary Resources: Adam J. Levitin, In Defense of Bailouts, 99 Geo. L. J. 435 (2011); Steven C. Caywood, Note, Wasting the Corporate Waste Doctrine: How the Doctrine Can Provide a Viable Solution in Controlling Excessive Executive Compensation, 109 Mich. L. Rev. 111 (2010). (6.5)

Subtotal II

III. Basic Answer (in what direction do you see the research going?) (10 points)

IV. Format (20 points)

a. Clear and concise presentation; professional product (concise, ability to follow, grammar, page numbers, absence of typos, generally follows instructions, page limit) (10)

b. Citation (10)

TOTAL

\section{APPENDIX C}

Form of Generic Plan/Ruberic

I. Preliminary Metholodogy (20 points)

a. Issue(s) correctly identified and concisely stated (find the crux of the problem) (4)

b. Client and objective identified (i.e., what does the client want the lawyer to do for them?) (4)

c. Clear statement of facts (concise, objective, accurate) (4)

d. Identification of need for additional facts (show that you know what you do not know) (4)

e. Jurisdiction identified (show the scope of your research, show where and to whom your results will apply) (4)

II. Methodology and Authority (50 points)

a. Statement of strategy (how will you best spend your time to benefit your client; how will you approach the problem?) (10)

b. Search terms (rich, thoughtful, useful) (5)

c. Potential sources (list the potential sources and why they would be relevant to the research question, as well as their level of authority) (5) 
d. Discussion of use of source and why within context of strategy (why does this potential source's relevance, authority, etc. make it a good source for this assignment?) (10)

e. Identification of primary authority (list mandatory sources identified as actually useful or sources you must address and why) (10)

f. Identification of secondary authority (list sources identified as actually useful and why useful [i.e., points to primary authority, explanatory]) (10)

III. Basic answer (in what direction do you see the research going?) (10)

IV. Format (20)

a. Clear, concise presentation (10)

b. Citation (10) 